\title{
A Longitudinal Evaluation of Partial Lung Irradiation in Mice by Using a Dedicated Image-Guided Small Animal Irradiator
}

Citation for published version (APA):

Granton, P. V., Dubois, L., van Elmpt, W., van Hoof, S. J., Lieuwes, N. G., De Ruysscher, D., \& Verhaegen, F. (2014). A Longitudinal Evaluation of Partial Lung Irradiation in Mice by Using a Dedicated Image-Guided Small Animal Irradiator. International Journal of Radiation Oncology Biology Physics, 90(3), 696-704. https://doi.org/10.1016/j.ijrobp.2014.07.004

Document status and date:

Published: 01/11/2014

DOI:

10.1016/j.ijrobp.2014.07.004

Document Version:

Publisher's PDF, also known as Version of record

\section{Document license:}

Taverne

Please check the document version of this publication:

- A submitted manuscript is the version of the article upon submission and before peer-review. There can be important differences between the submitted version and the official published version of record.

People interested in the research are advised to contact the author for the final version of the publication, or visit the DOI to the publisher's website.

- The final author version and the galley proof are versions of the publication after peer review.

- The final published version features the final layout of the paper including the volume, issue and page numbers.

Link to publication

\footnotetext{
General rights rights.

- You may freely distribute the URL identifying the publication in the public portal. please follow below link for the End User Agreement:

www.umlib.nl/taverne-license

Take down policy

If you believe that this document breaches copyright please contact us at:

repository@maastrichtuniversity.nl

providing details and we will investigate your claim.
}

Copyright and moral rights for the publications made accessible in the public portal are retained by the authors and/or other copyright owners and it is a condition of accessing publications that users recognise and abide by the legal requirements associated with these

- Users may download and print one copy of any publication from the public portal for the purpose of private study or research.

- You may not further distribute the material or use it for any profit-making activity or commercial gain

If the publication is distributed under the terms of Article $25 \mathrm{fa}$ of the Dutch Copyright Act, indicated by the "Taverne" license above, 


\title{
A Longitudinal Evaluation of Partial Lung Irradiation in Mice by Using a Dedicated Image-Guided Small Animal Irradiator
}

\author{
Patrick V. Granton, PhD, ${ }^{*}$ Ludwig Dubois, PhD, ${ }^{*}$ Wouter van Elmpt, PhD, * \\ Stefan J. van Hoof, MSc, ${ }^{*}$ Natasja G. Lieuwes, BASc, ${ }^{*}$ \\ Dirk De Ruysscher, MD, PhD, ${ }^{* \dagger}$ and Frank Verhaegen, $\mathrm{PhD}^{* \dagger}$
}

\author{
*Department of Radiation Oncology (MAASTRO), GROW-School for Oncology and Developmental \\ Biology, Maastricht University Medical Center, Maastricht, the Netherlands; ${ }^{\dagger}$ Radiation Oncology, \\ University Hospitals Leuven/KU Leuven, Belgium; and ${ }^{\ddagger}$ Medical Physics Unit, Department of \\ Oncology, McGill University, Montréal, Québec, Canada
}

Received Feb 25, 2014, and in revised form Jul 2, 2014. Accepted for publication Jul 4, 2014.

\section{Summary \\ Partial lung irradiation with doses between 4 and 20 Gy in C57BL/6 mice $(\mathrm{n}=76)$ was performed with repeated micro-computed tomography (CT) imaging over 39 weeks. Significant differences in CT numbers between the 20-Gy and control group were observed, with a mean dif- ference of $120 \pm 10 \mathrm{HU}$ at week 39. The onset of radiation-induced lung fibrosis observed was later and the severity was less than that in previous reports for}

\begin{abstract}
Purpose: In lung cancer radiation therapy, the dose constraints are determined mostly by healthy lung toxicity. Preclinical microirradiators are a new tool to evaluate treatment strategies closer to clinical irradiation devices. In this study, we quantified local changes in lung density symptomatic of radiation-induced lung fibrosis (RILF) after partial lung irradiation in mice by using a precision imageguided small animal irradiator integrated with micro-computed tomography (CT) imaging.

Methods and Materials: C57BL/ 6 adult male mice $(n=76)$ were divided into 6 groups: a control group ( $0 \mathrm{~Gy})$ and groups irradiated with a single fraction of 4 , $8,12,16$, or 20 Gy using 5-mm circular parallel-opposed fields targeting the upper right lung. A Monte Carlo model of the small animal irradiator was used for dose calculations. Following irradiation, all mice were imaged at regular intervals over 39 weeks (10 time points total). Nonrigid deformation was used to register the initial micro-CT scan to all subsequent scans.

Results: Significant differences could be observed between the 3 highest ( $>10 \mathrm{~Gy}$ ) and 3 lowest irradiation ( $<10 \mathrm{~Gy}$ ) dose levels. A mean difference of $120 \pm 10 \mathrm{HU}$ between the 0- and 20-Gy groups was observed at week 39. RILF was found to be spatially limited to the irradiated portion of the lung.
\end{abstract}

Reprint requests to: Dr Frank Verhaegen, PhD, Department of Radiation Oncology, Maastricht University Medical Center, GROW School for Oncology and Developmental Biology, 6201 BN Maastricht, The Netherlands. Tel: +31 88 4455792; E-mail: frank.verhaegen@maastro.nl

Financial support for the purchase and operation of the microirradiator was provided by Marie Curie grant PIRG03-GA-2008-230911, Netherlands Organisation for Health Research and Development grant 40-00506-98-9019, and the GROW research institute. Financial support for

\footnotetext{
the study was provided by Boehringer-Ingelheim International $\mathrm{GmbH}$ grant 43040512. PVG is supported by a 3 year Postgraduate Scholarship from the Natural Sciences and Engineering Research Council of Canada. P.V. Granton and L. Dubois contributed equally to this work.

Conflict of interest: none.

Supplementary material for this article can be found at www.redjournal.org.
} 
whole- or hemithorax irradiations of the same prescription dose.
Conclusions: The data suggest that the severity of RILF in partial lung irradiation compared to large field irradiation in mice for the same dose is reduced, and therefore higher doses can be tolerated. (C) 2014 Elsevier Inc.

\section{Introduction}

Lung cancer remains the most common type of cancer worldwide, and strategies are needed to improve local tumor control (1). The dose-limiting toxicity of radiation therapy with or without drugs is acute stage radiationinduced lung pneumonitis or late stage radiation-induced lung fibrosis (RILF). Advances in radiation dose delivery such as stereotactic body radiation therapy and intensity modulated radiation therapy have been shown to minimize the rate of treatment complications by avoiding radiation to normal lung tissue (2-4). However, despite recognition of radiation-induced lung injury (RILI) as early as the use of radiation therapy itself, treatment strategies to alleviate lung toxicity have hitherto been largely ineffective (5).

Preclinical small animal models of RILI are a means to evaluate new treatment strategies that would be unethical to investigate in patients and allow for studies with large cohorts, transgenic animals, controlled experimental conditions, and accelerated results due to the shorter lifespans. The use of computed tomography (CT) imaging to noninvasively monitor changes in lung morphology, principally changes in lung density, due to RILI has been successfully applied in both clinical (6-9) and preclinical studies (10-15). However, most of these previous preclinical studies were performed using large radiation fields often covering the whole thorax, with relatively coarse clinical resolution CT imaging and limited knowledge of where radiation was delivered. The clinical utility of the results of these studies may be limited due to the radiation dose distributions being highly dissimilar to current radiation therapy practice.

Dedicated precision image-guided small animal irradiation (IR) devices are now available that better mimic clinical radiation therapy, making them potentially better suited to study and quantify RILI (16-18). These devices provide unparalleled targeting accuracy with registered CT irradiation technology that allows researchers to directly study the response of structures to the known regions of irradiation. Within this context, the focus of this study was to develop advanced methods including deformable registration, image segmentation, and full 3-dimensional (3D) accurate dose calculations for small radiation fields to quantify local changes in lung density following precision irradiation in mice. We aimed to place the results within the context of previous irradiation studies that did not make use of these advanced techniques. We used high-resolution micro-CT to monitor a large cohort of fibrosis-prone C57BL/6 mice for an extended period of 39 weeks of observation, which is longer than that of any previous study.

\section{Methods and Materials}

\section{Selection of subjects}

C57BL/6 adult male mice $(n=76)$ at 12 weeks of age entered the study and are known to be prone to fibrosis (19, 20). Animal experiments were in accordance with local institutional guidelines for animal welfare and approved by the Animal Ethical Committee of the University (number 2012-006). Animals were divided into 6 groups, corresponding to 6 radiation dose levels, with each group containing at least 11 animals. Before and subsequent to irradiation, all mice were imaged using micro-CT at regular intervals for a total of 39 weeks (ie, 10 imaging time points) as illustrated in the timeline in Figure 1. Animals were anesthetized using isoflurane (induction 4\%, maintenance $1.5 \%-2 \%$ ) and permitted to breath freely during the imaging and irradiation procedures. Animals were monitored daily for signs of compromised health and were weighted at each imaging session.

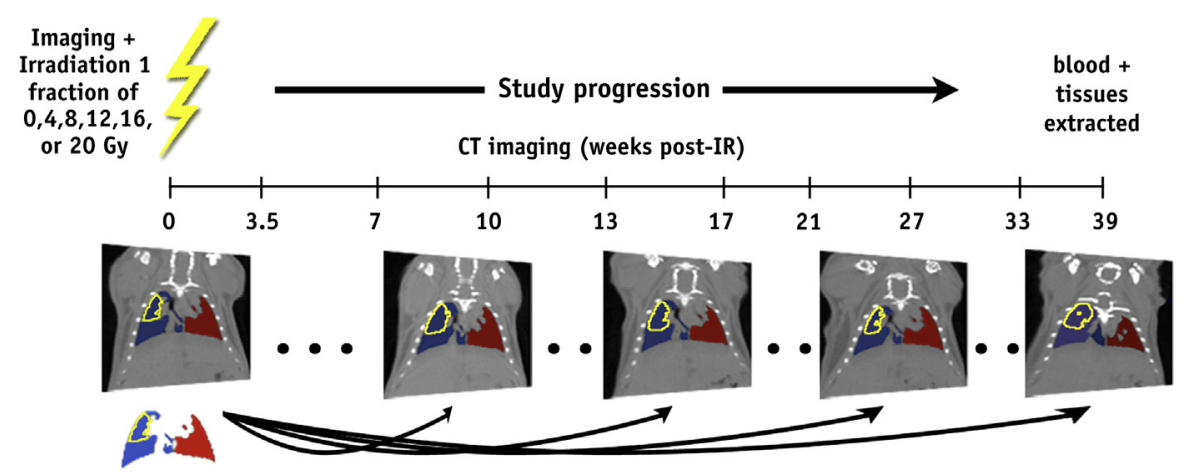

Fig. 1. The study design and illustration of the deformation process show the propagation of the lung and dose contours from the initial CT image to all subsequent CT images. CT = computed tomography. 


\section{Small animal microirradiator}

The small animal microirradiator (micro-IR; X-RAD 225Cx; Precision X-ray, Inc, North Branford, CT) with an integrated micro-CT has been previously described $(16,18$, 21). A high-resolution $80-\mathrm{kVp}, 2.5-\mathrm{mA}$ imaging protocol filtered by $2-\mathrm{mm}$ Al with an acquisition rate of 5 frames/ second and a gantry rotation of 1 revolution/minute was used for all imaging. Image projections were acquired and reconstructed using the Feldkamp filtered back projection (Pilot version 1.1.18; Precision X-ray, Inc), resulting in a final reconstructed isotropic pixel spacing of $102 \mu \mathrm{m}$ and a standard deviation of $20 \mathrm{HU}$ within a sufficiently large region of interest (100 voxels) in a uniform medium such as water. The total micro-CT imaging skin dose for this procedure was $39 \mathrm{cGy}$, which should have had no adverse effects for the frequency and duration of the study (22).

Parallel-opposed beams $5 \mathrm{~mm}$ in diameter were used to irradiate the upper right lung of the mice in an area of minimal displacement of the lung during breathing. Animals were irradiated with parallel-opposed $\mathrm{x}$-ray beams (225 kVp, with $0.3 \mathrm{~mm} \mathrm{Cu}$ added for filtration) at $12 \mathrm{~mA}$ with radiation doses of $4,8,12,16$, and $20 \mathrm{~Gy}$, equally divided over the 2 beams for irradiation times of 88, 176, 264, 352, and 440 seconds. The dose prescription was defined to a point (ie, target voxel) within the upper right lung following completion of the CT image. During treatment, this location was also the mechanical isocenter of the beams. A control group received 0 Gy. To spare the heart and spine from unwanted irradiation, the beam angle with the best avoidance was chosen. To extract CT data from a lung subregion in the control group that received no radiation, to compare to groups that did receive irradiation, beam angles were chosen and dose calculations were performed as if the group had received radiation.

\section{Dose calculations}

Dose calculations were performed with DOSXYZnrc software (rev. 1.47; National Research Council Canada, Ottowa, ON) (23) with a validated Monte Carlo (MC) source model in voxelized geometries based on the CT image data (21) containing an intrinsic experimental dose uncertainty of $4 \%$ or 0.8 Gy for the $20-\mathrm{Gy}$ dose prescription. For MC dose calculations, both the material (ie, crosssectional data) and density are required and are assigned on a voxel-by-voxel basis according to the CT number (16). The conversion of CT number to material type and density was performed based on a 4-material CT number threshold scheme and a density calibration curve, using materials of known composition and density (24). The 4-material classes were air, lung, soft tissue, and cortical bone (ICRU report 44 [25]). Tissues were segmented using software that permits the user to visualize materials overlaid by CT data and adjust CT thresholds accordingly based on a sliding window visualization (26). Ten micro-CT image volumes from different mice were segmented, and 3 threshold values were averaged. Dose calculations were run with $5 \times 10^{8}$ photons and energy cutoffs for the photon (PCUT) and electron (ECUT) transport of 10 and $100 \mathrm{keV}$, respectively, and reached a statistical uncertainty less than $1 \%$ in the target region. Regions bounded by the $80 \%$ isodose to max lung dose, and $2 \%$ isodose and below, represented the irradiated and out-of-field regions within the irradiated lung.

\section{Deformable registration}

The lung geometry of a mouse varies at different time points for several reasons. Deformable registration was required in this study to track the location of the irradiated portion of lung in the micro-CT images acquired at different imaging time points. For each mouse, 3D contours (ie, masks) of the left and right lung were generated using the initial micro-CT image volume in a semiautomatic manner and visually checked. Using the material segmented micro-CT images, we selected mouse lungs and isolated them from their surroundings by region growing lung voxels. The isolated lungs were then segmented into right and left lung by a plane passing through the spine and the sternum. To reduce the sensitivity of the lung boundaries influencing the mean CT numbers of the lung, each lung contour surface was eroded by 2 voxels (ie, $204 \mu \mathrm{m}$ ).

Deformable registration was performed with all microCT images using software developed in-house that allows for batch runs through command scripting (27). The initial micro-CT image volume was registered (ie, nonrigidly deformed) to every subsequent micro-CT image so that only contours were propagated from the initial micro-CT image to all subsequent CT images. Downsampling by a factor of 3 (ie, reducing the isotropic pixel spacing from $102 \mu \mathrm{m}$ to $306 \mu \mathrm{m}$ ) was performed with both image volumes to achieve a smoother and continuous deformation field. Rigid followed by deformable registration was performed based on parameters outlined in the next section. The deformation fields were then resampled to the original isotropic spacing and deformations applied to the lung and dose contours. An illustration of the application of the deformed contours is given in Figure 1.

\section{Deformable registration volume correspondence}

We tested the 2 frequently used deformation algorithms of CT images, Demons and Morphons (27). In 6 mice, deformed lung contours of the last imaging time point, 3 with apparent changes in lung morphology and 3 without any major changes in lung morphology were compared against lung contours delineated by an individual experienced in mouse anatomy. Two parallel runs of 8 (16 combinations total) deformable nonrigid registration parameters were evaluated (see Supplementary Table 1) relative to the 
oncologist's lung contours using a Dice overlap ratio defined as.

$$
D R=\left(\frac{2 \times V_{M A N \cap D S A}}{V_{M A N}+V_{D S A}}\right)
$$

where $\mathrm{V}$ is the volume defined by the delineated lung and the subscripts MAN and DSA indicate the lung contours determined manually and the deformed semiautomated lung contours. The deformation parameters resulting in the best Dice ratio were used on all the acquired images for $\mathrm{CT}$ density analysis for all mice.

\section{Image analysis}

Once the lung and dose contours had been propagated to all subsequent micro-CT scans using deformable registration, four regions of interest (ROI) were established, defined as right and left lung (ROI.1 and 2, respectively), the irradiated region of the right lung (ROI.1a), and the nonirradiated portion of the right lung (ROI.1b). An illustration of the segmentation of the CT and dose data to ROI can be seen in Figure 2. The mean CT number and standard deviation inside each of these regions were calculated for each mouse for all ten CT imaging time points. ROI.1b and ROI.2 were used as controls of changes in ROI.1a. The differences in CT number between the regions (1a vs $1 \mathrm{~b}$; and $1 \mathrm{a}$ vs 2 ) within each CT image in time (normalized to the initial CT scan) were calculated for each mouse and averaged according to dose group. All lung and dose volume nonrigid deformations were inspected visually; if either resulted in obviously incorrect results, those measurements were excluded from the analysis.

\section{Results}

Animals appeared healthy for the duration of the study; their body weights steadily increased over the 39-week study endpoint (see supplementary Fig. SA). The whole cohort of mice was imaged and irradiated within 17 hours spread over 2 days. In the subsequent micro-CT imaging follow-up, we achieved a throughput time of 6 minutes per animal per imaging session. In a subset analysis of 6 mice, animal breathing remained principally in a state of maximum exhalation with the diaphragm relaxed, with approximately $13 \%$ of the respiratory cycle in a state of inhalation and motion. Increased lung density, consistent with the development of fibrotic tissue, could be observed visually in CT images in the late stage imaging time points for mice irradiated with higher dose levels, confirming that RILF could be induced in partial lung irradiation as compared to a mouse that received no irradiation (Fig. 3A and $\mathrm{B}$ ).

MC dose calculations resulted for the different dose groups in an average \pm standard deviation dose of $3.8 \pm 0.1,7.6 \pm 0.1,11.3 \pm 0.1,15.0 \pm 0.1$, and $19.0 \pm 0.2$ Gy in the $80 \%$ to maximum irradiated lung region; for simplicity we refer to these irradiation doses as nominal 4, 8, 12, 16, and $20 \mathrm{~Gy}$. The CT thresholds segmenting air, lung, soft tissue, and cortical bone among 3 researchers familiar with animal pathology were found to be $-655 \pm 6,-102 \pm 17$, and $383 \pm 15 \mathrm{HU}$, indicating they were very similar for all animals. Dose-volume histograms (DVH) of the whole lung for the different irradiation groups can be seen in Figure 4. The prescription dose of 4 to $20 \mathrm{~Gy}$ was reached in approximately $10 \% \pm 3.5 \%$ of the total lung volume of mice. As can be seen from the DVHs, the parallel-opposed fields provided for a well-defined shoulder (fall-off), and the beams were highly conformal to a localized lung region, as shown in Figure 2.

The validation and performance of the nonrigid registration between oncologist's delineated lung contours compared to segmented and deformed lung contours of six mice resulted in an average Dice ratio of $0.83 \pm 0.02$ for the average of both lungs for all mice. The performance of the deformations was not influenced in those mice with visible signs of fibrosis. The best performing deformation algorithm was the Demons algorithm; for the specific deformation parameters, see supplementary appendix Table $\mathrm{S} 1$. The total calculation time for the deformable registration was approximately 80 minutes per animal (ie, 9 deformations in total).

Visual inspection of all deformations led to the discovery of occasionally unsuccessful deformations, resulting in contours that were outside of the lung. Typically this occurred when there were significant changes in the physiology of the irradiated right lung as seen in the CT images (eg, pleural infusions [28]), but these events were usually transient and not apparent in the subsequent CT scan. In total, $3 \%$ of the CT data from the irradiated region (ROI.1a) was excluded from analysis due to obvious errors in the deformation.

The change in CT number over time between the irradiated right lung region (Fig. 2, ROI.1a) and the left lung (Fig. 2, ROI.2) resulted in significant differences between the high-dose group and the group that received no irradiation between the initial CT scan and the last scan. However, it was found that for $25 \%$ of the left lung (ROI.2), significant morphological changes (eg, compressed, collapsed, or fluid filled) did not permit an adequate comparison and therefore reduced the statistical power of the groups. Instead, the nonirradiated region (ROI.1b) of the irradiated lung was found to be a good surrogate. Figure 5 shows CT number differences between the 2 regions (ROI.1a vs $1 \mathrm{~b}$ ) of the irradiated right lung compared to the remaining valid data of the left lung for dose groups $12 \mathrm{~Gy}, 20 \mathrm{~Gy}$ and no irradiation. Principal changes in lung density were contained in the irradiated region; therefore, ROI.1 b could be used as a control. The change in CT number between ROI.1a and ROI.1b is illustrated in Figure 6 for all dose groups and time points. At the 39th week endpoint, there was a difference of $120 \pm 20 \mathrm{HU}$ between the $20 \mathrm{~Gy}$ and 0 Gy groups, which was significant $(P<.001)$. From 7.5 weeks postirradiation, 

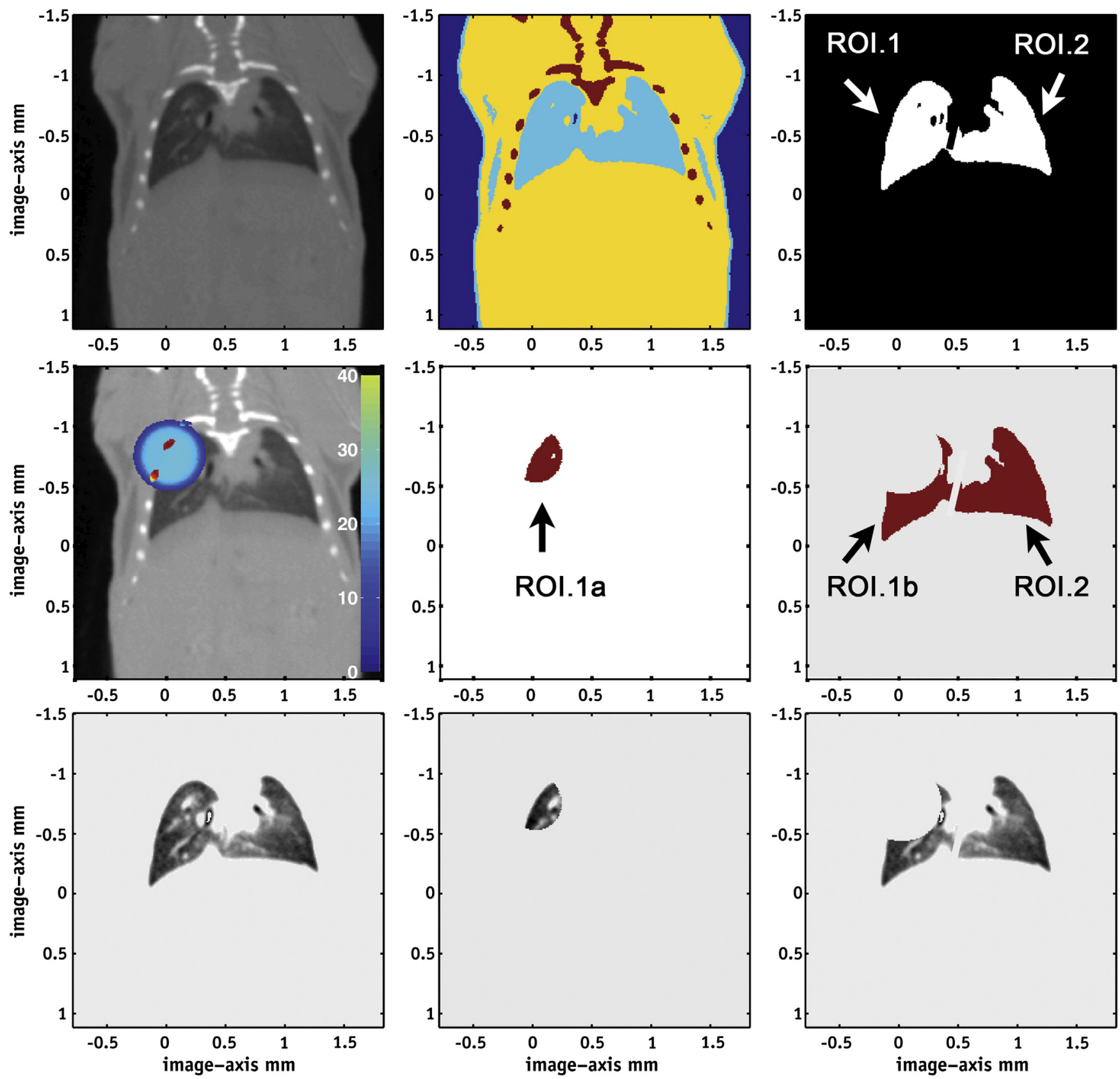

Fig. 2. Segmentation of the $\mathrm{CT}$ and dose data into regions of interest is shown. The top row illustrates the segmentation of the axial CT slice into appropriate tissues components and the isolation of the lungs. The middle row shows the dose deposition, the segmentation of the dose region ( $80 \%$ to maximum), and the intersection of the region exposed to $>80 \%$ dose with the lung region (ROI. 1a). ROI. 1b represents the nonirradiated region of the right lung with bounds defined at $<2 \%$ of the maximum lung dose. ROI. 2 is the segmented nonirradiated left lung. The bottom row shows CT data of the regions of interest. CT $=$ computed tomography.

there was a clear incremental change in CT number for the 20-Gy dose group.

\section{Discussion}

This study demonstrates the feasibility of large animal cohort radiation studies that are more representative of clinical irradiation schemes. Following the seventh week postirradiation, C57/BL6 male mice irradiated with 5-mm parallel-opposed beams of prescription doses greater than 10 Gy exhibited a steady increase in lung density most pronounced for the 20-Gy group, having a maximum difference of $120 \mathrm{HU}$ at the 39th week endpoint compared to the zero dose group. We have shown that partial lung irradiation can induce symptoms characteristic of RILF that are discernable as early as 10 weeks postirradiation compared to the nonirradiated group. While the 

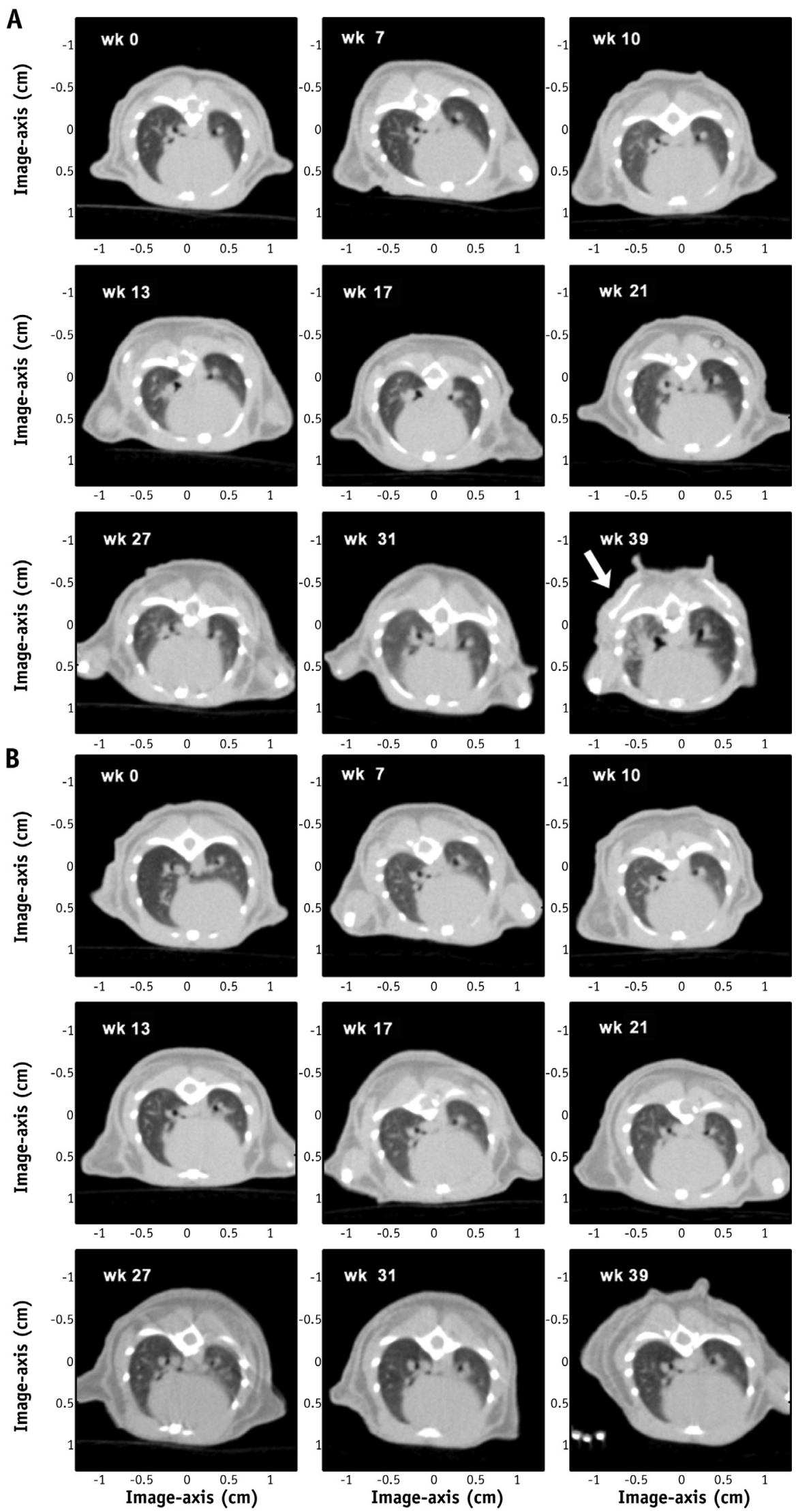

Fig. 3. Sequential CT axial images per week of a mouse, with visible changes in lung density (A) consistent with radiationinduced lung fibrosis appearing in the last weeks of the study, after a dose of $20 \mathrm{~Gy}$ (arrow), and (B) a nonirradiated mouse image series with no visible changes in lung density. CT = computed tomography. 


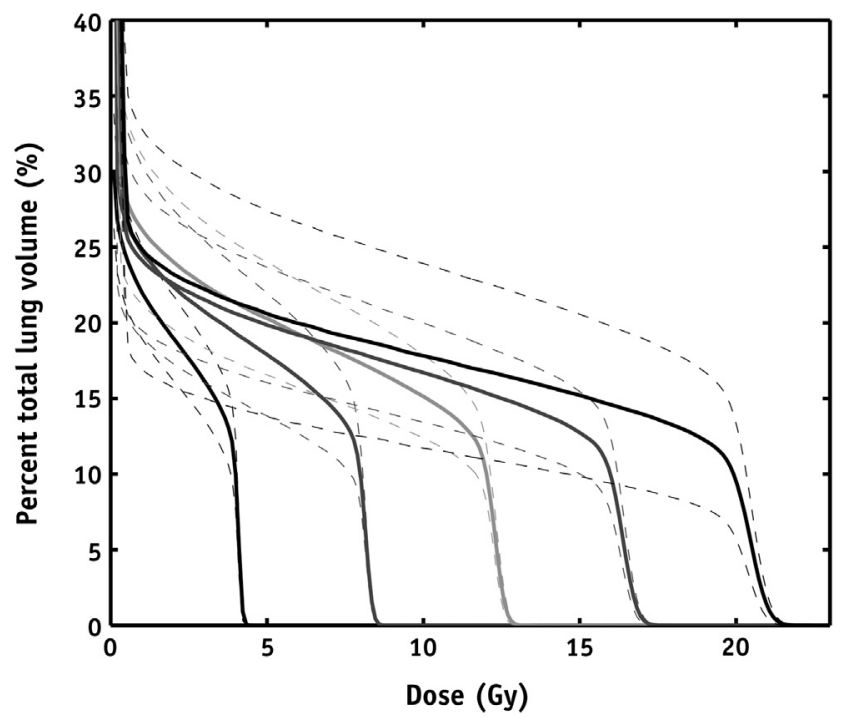

Fig. 4. Dose-volume histograms in the total lungs (left and right lung) of the different mouse dose groups exposed to $4,8,12,16$, and $20 \mathrm{~Gy}$, with the dashed lines representing the standard deviation within each group, demonstrating the variation in irradiated mice lung volume when using the same size 5-mm field of irradiation.

manifestation of RILF may be evident only visually in CT images at late stages, analysis of CT data can show early (10 weeks post-IR) the development RILF.

We have also demonstrated the use of deformable registration for longitudinal animal studies to accurately deform mice lung contours from an initial CT scan to subsequent follow-up CT scans, without which the study would be susceptible to operator-specific lung contour delineation. The use of deformable registration also significantly speeds up the data analysis and allows for processing large datasets in reasonable times. We found no significant difference with the experienced person familiar with animal anatomy contouring in the performance of the deformation for the 3 mice with visible signs of RILF compared to mice without any sign of RILF.

Data shown in Figure 6 demonstrate the progression of the disease for partial lung irradiation that has not been seen previously at such a temporal resolution. Interestingly, an increase in CT number present in all high-dose groups $(12,16$, and $20 \mathrm{~Gy})$ was found at the second time point, 3.5 weeks post-IR, potentially attributed to radiationinduced lung pneumonitis. Despite significant differences between the low- and high-dose groups, a clear differentiation for all other irradiations between 0 and $20 \mathrm{~Gy}$ is absent for a single time point but evident when considering all the time points greater than 10 weeks (to avoid potential confusion with any pneumonitis event) as seen in the dose response curve of the summed CT differences (see supplementary Fig. B).

When we compared the prescription dose of our study to that of other similar studies, the onset of lung density changes appears to happen later, and the severity of those changes appears to be lower in our study. In a study by Plathow et al (13), CT density changes of greater than 200 HU were observed 21 weeks postirradiation, whereas in our study, we saw differences of only approximately $60 \mathrm{HU}$ for the same prescription and observation time point; neither did we observe any deaths, as in whole-thorax irradiation studies of the same prescription dose (13). Travis et al (29) also saw significant morbidity for similar levels of irradiation between 14 and 20 Gy in larger volume partial lung irradiations of mice (29). The lower severity of the partial volume irradiation in this study ( $\% 15$ total lung volume) is not surprising given that previous histopathological analysis of RILF studies have previously shown that
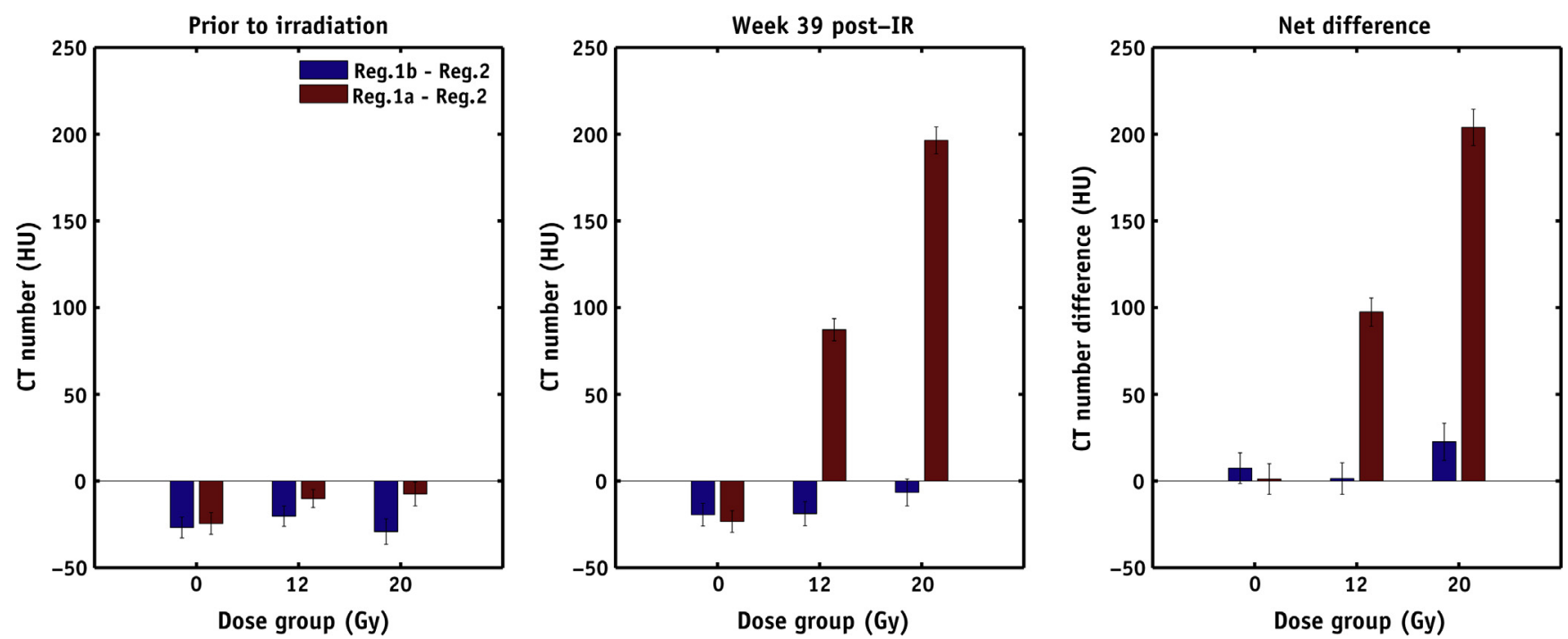

Fig. 5. Change in CT number compared between the irradiated and nonirradiated portions of the right lung (ROI.1a, ROI.1b.) compared to those in the nonirradiated left lung (ROI. 2) at the beginning and at the end of the 39-week study for the 12 and 20 Gy and zero dose level groups. CT = computed tomography. 


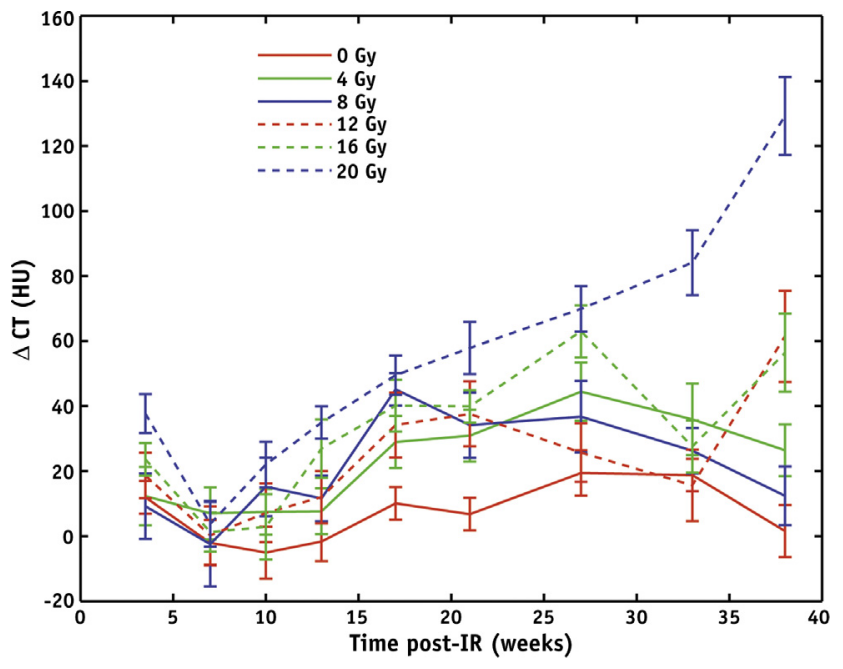

Fig. 6. Change in CT number over time for the 6 levels of irradiation between the right irradiated lung region (ROI.1a) and the region of the right lung that was primarily outside the field (ROI.1b). CT = computed tomography.

whole-body mouse irradiations of 12 to 15 Gy resulted in the presence of fibrosis in week 20, whereas thorax-limited irradiations of the same dose prolonged the onset of fibrosis to week 24 (30). Our findings, which could not have been quantified to the same level of accuracy and precision without state-of-the-art techniques used in this study, give credence to the observed volume effect. It will allow future studies to pursue dose escalation and provide opportunities to better understand radiation-induced lung toxicity in stereotactic body radiation therapy (31).

Surprisingly, we found that the use of the left lung as a control for the change in CT number of the irradiated region was unreliable in a significant portion of mice ( $\sim 25 \%)$, which is likely due to the free positioning of the animals on their abdomen combined with location of the heart. Fortunately, RILF was limited to the irradiated region of the lung alone, allowing the use of the right irradiated lung region outside of the field to be used as a control, as shown in patients $(32,33)$. However, future studies may wish to investigate the use of conformal beds or forced breath-hold techniques to reduce animal setup variability (34), although the added benefit of these techniques will have to be weighed against cost and time constraints.

\section{Conclusions}

Presently, we are faced with a wealth of new compounds that may be combined with radiation therapy; nearly none of the novel drugs has been investigated in animals with regard to normal tissue damage. Indeed, results from preclinical animal experiments cannot be translated directly to humans, but at least an indication of the side effects as well as the genetic or mechanistic basis for the interaction may arise. In that context, normal tissue work may be more readily extrapolated from mice to humans than from xenografts to patients, where the predictive value of tumor work has been increasingly challenged. The new highprecision animal irradiation platforms may thus allow testing of several compounds and combinations of medication and radiation in normal tissue models in mice with different genetic backgrounds and with specific diseases. This may allow clinicians to assess the best strategy to widen the therapeutic window when designing clinical studies. Our study employed a radiation field size that is proportionally more realistic to clinical experience than previously published semi- or full-thorax irradiations, which has been used frequently in mice. We hope that future preclinical studies may benefit from this study given that there is a growing community of users, in particular for normal tissue toxicity studies or for more realistic models of disease like new orthotopic tumor models (eg, for nonsmall cell lung cancer).

\section{References}

1. Ferlay J, Shin HR, Bray F, et al. Estimates of worldwide burden of cancer in 2008: GLOBOCAN 2008. Int J Cancer 2010;127:2893-2917.

2. Koto M, Takai Y, Ogawa Y, et al. A phase II study on stereotactic body radiotherapy for stage I non-small cell lung cancer. Radiother Oncol 2007;85:429-434.

3. Lanni TB Jr, Grills IS, Kestin LL, et al. Stereotactic radiotherapy reduces treatment cost while improving overall survival and local control over standard fractionated radiation therapy for medically inoperable non-small-cell lung cancer. Am J Clin Oncol 2011;34:494-498.

4. Jang WI, Kim MS, Bae SH, et al. High-dose stereotactic body radiotherapy correlates increased local control and overall survival in patients with inoperable hepatocellular carcinoma. Radiat Oncol 2013; $8: 250$.

5. Westbury CB, Yarnold JR. Radiation fibrosis-current clinical and therapeutic perspectives. Clin Oncol 2012;24:657-672.

6. De Ruysscher D, Sharifi H, Defraene G, et al. Quantification of radiation-induced lung damage with $\mathrm{CT}$ scans: The possible benefit for radiogenomics. Acta Oncol 2013;52:1405-1410.

7. Palma DA, van Sornsen de Koste JR, Verbakel WF, et al. A new approach to quantifying lung damage after stereotactic body radiation therapy. Acta Oncol 2011;50:509-517.

8. Jenkins P, Welsh A. Computed tomography appearance of early radiation injury to the lung: Correlation with clinical and dosimetric factors. Int J Radiat Oncol Biol Phys 2011;81:97-103.

9. Bernchou U, Schytte T, Bertelsen A, et al. Time evolution of regional CT density changes in normal lung after IMRT for NSCLC. Radiother Oncol 2013;109:89-94.

10. El-Khatib E, Sharplin J, Battista J. The density of mouse lung in vivo following X irradiation. Int J Radiat Oncol Biol Phys 1983;9:853-858.

11. Van Dyk J, Hill RP. Post-irradiation lung density changes measured by computerized tomography. Int J Radiat Oncol Biol Phys 1983;9:847-852.

12. Nicholas D, Down JD. The assessment of early and late radiation injury to the mouse lung using X-ray computerised tomography. Radiother Oncol 1985;4:253-263.

13. Plathow C, Li M, Gong P, et al. Computed tomography monitoring of radiation-induced lung fibrosis in mice. Invest Radiol 2004;39:600-609.

14. Saito S, Murase K. Detection and early phase assessment of radiationinduced lung injury in mice using micro-CT. PLoS One 2012;7: e45960.

15. Ghobadi G, Hogeweg LE, Faber H, et al. Quantifying local radiationinduced lung damage from computed tomography. Int J Radiat Oncol Biol Phys 2010;76:548-556. 
16. Verhaegen F, Granton P, Tryggestad E. Small animal radiotherapy research platforms. Phys Med Biol 2011;56:R55-83.

17. Wong J, Armour E, Kazanzides P, et al. High-resolution, small animal radiation research platform with $\mathrm{x}$-ray tomographic guidance capabilities. Int J Radiat Oncol Biol Phys 2008;71:1591-1599.

18. Clarkson R, Lindsay P, Ansell S, et al. Characterization of image quality and image guidance performance of a pre-clinical micro-irradiator. Med Phys 2010;38:845-856.

19. Hallahan DE, Geng L, Shyr Y. Effects of intercellular adhesion molecule 1 (ICAM-1) null mutation on radiation-induced pulmonary fibrosis and respiratory insufficiency in mice. J Natl Cancer Inst 2002;94:733-741.

20. Rube CE, Uthe D, Schmid KW, et al. Dose-dependent induction of transforming growth factor beta (TGF-beta) in the lung tissue of fibrosis-prone mice after thoracic irradiation. Int J Radiat Oncol Biol Phys 2000;47:1033-1042.

21. Granton PV, Podesta M, Landry G, Nijsten S, Bootsma G, Verhaegen F. A combined dose calculation and verification method for a small animal precision irradiator based on onboard imaging. Med Phys 2012:39:4155-4166.

22. Detombe SA, Dunmore-Buyze J, Petrov IE, et al. X-ray dose delivered during a longitudinal micro-CT study has no adverse effect on cardiac and pulmonary tissue in C57BL/6 mice. Acta Radiol 2013.

23. Walters BRB, Kawrakow I, Rogers D. DOSXYZnrc users manual. Ottawa, ON: National Research Council of Canada; 2011.

24. Verhaegen F, van Hoof S, Granton PV, Trani D. A review of treatment planning for precision image-guided photon beam pre-clinical animal radiation studies. Z Med Phys 2014.

25. International Commission on Radiation Units. ICRU report 44, tissue substitutes in radiation dosimetry and measurement. 1989;46.
26. van Hoof SJ, Granton PV, Verhaegen F. Development and validation of a treatment planning system for small animal radiotherapy: SmART-Plan. Radiother Oncol 2013.

27. Janssens G, Jacques L, Orban de Xivry J, et al. Diffeomorphic registration of images with variable contrast enhancement. Int $J$ BIomed Imaging 2011;2011:1-12.

28. Jackson IL, Vujaskovic Z, Down JD. Revisiting strain-related differences in radiation sensitivity of the mouse lung: Recognizing and avoiding the confounding effects of pleural effusions. Radiat Res 2010;173:10-20.

29. Travis EL, Liao ZX, Tucker SL. Spatial heterogeneity of the volume effect for radiation pneumonitis in mouse lung. Int J Radiat Oncol Biol Phys 1997;38:1045-1054.

30. Moore BB, Hogaboam CM. Murine models of pulmonary fibrosis. Am J Physiol Lung Cell Mol Physiol 2008;294:L152-160.

31. Cho J, Kodym R, Seliounine S, et al. High dose-per-fraction irradiation of limited lung volumes using an image-guided, highly focused irradiator: Simulating stereotactic body radiotherapy regimens in a small-animal model. Int J Radiat Oncol Biol Phys 2010;77: 895-902.

32. Vinogradskiy Y, Diot Q, Kavanagh B, et al. Spatial and dose-response analysis of fibrotic lung changes after stereotactic body radiation therapy. Med Phys 2013;40:081712.

33. Stroian G, Martens C, Souhami L, et al. Local correlation between Monte Carlo dose and radiation-induced fibrosis in lung cancer patients. Int J Radiat Oncol Biol Phys 2008;70:921-930.

34. Artaechevarria X, Blanco D, Perez-Martin D, et al. Longitudinal study of a mouse model of chronic pulmonary inflammation using breath hold gated micro-CT. Eur Radiol 2010;20:2600-2608. 